\title{
Türkiye'de İletişim Alanında Düzenlenen Akademik Etkinlikler (Kongre, Konferans, Sempozyum) Üzerine Bir Değerlendirme (2018-2020)
}

\section{Mehmet ULAŞ*}

Toplumsal olarak içinde bulunduğumuz dönem; üretilen bilgilerin, fikirlerin, beğenilerin ve kanaatlerin anlık olarak başkaları ile paylaşılabildiği bir "Dijital Çağ" olarak tanımlanabilir. Bu çağı diğerlerinden ayıran argümanların başında zaman ve mekân mefhumunun dönüştürülerek sınırlılıların öteki hâline gelmesi gerçekliği yer almaktadır. Sosyal bilimler perspektifinden bakıldığında birçok disipline göre yeni bir disiplin olan iletişim alanı, bu çağ ile bütünleşik bir birliktelik oluşturan alanların başında gelmektedir. Teknolojik anlamda yaşanan gelişmelerin insanların iletişim pratikleri üzerinde oluşturduğu form değişiklikleri göz önüne alındığında iletişim ve dijital arasında ortaya çıkan bu birliktelik doğal bir durumun yansıması niteliğindedir. Iletişim alanında yapılan çalışmaların teknolojik gelişmeler doğrultusunda ve teknosentrik bir şekilde ele alınmasının nihayetinde bu alan toplumsal yaşam pratiklerine, toplumun değerler dünyasına ve yaşamın alışılagelmiş formlarına değinen ve değişimini meydana getiren bir alana evrilmiştir. Toplumsal yaşamın ve bizatihi bireylerin üzerinde önemli bir etkiye sahip olan ve disiplinler arası bir niteliği barındıran iletişim alanı teknoloji ile oluşturduğu bütünleşik birliktelikle kritik öneme sahip bir alana dönüşmüştür.

Bu çalışmada sosyal ve beşeri bilimler alanında her geçen gün önemi artan ve disiplinler arası bir niteliğe sahip olması hasebiyle de diğer alanların da kavşak noktalarından birisi olan iletişim alanında 2018 yılı ve sonrasında üniversiteler, kamu kurumları ve yerel yönetimler tarafindan gerçekleştirilen kongrelerin, konferansların ve sempozyumların tespit edilmesi ve içerikleri hakkında bilgi verilmesi amaçlanmıştır. Buradan hareketle hazırlanan bu literatür çalışmasının, bu alana dair çalışma

*Arş. Gör. İnönü Üniversitesi, Mehmet.ulas@inonu.edu.tr, Orcid No: 0000-0002-6131-7509 DOI: $10.37679 /$ trta.945277 
yapacak olan araştırmacılar ve alana dair benzer etkinliklere katılmayı planlayan kişiler için yol gösterici bir başvuru kaynağı olması ümit edilmektedir. Bilimsel perspektifte bir alanın kurumsallaşabilmesinin başat unsurlarından biri, o alana yönelik kongre ve bilimsel etkinliklerin düzenlenmesidir (Balcı, 2008, s. 181-209). Akademik anlamda düzenlenen bu etkinlikler, alanın varlığını beyan eden bir gösterge niteliğindedir. Ayrıca alana dair katılımcıların özel ilgi alanlarının paylaşıldığı, tartışmaya sunulduğu ve yeniden tanımların yapıldığı bir sahanın varlığını temsil etmektedir (Oplatka, 2012, s. 21-27). Bu açıdan bakıldığında iletişim alanının varlığının anlamlı bir zemine oturmasına, entelektüel niteliğinin gelişimine, alanın sınırlarının belirlenmesine ve alana dair bilgilerin yeniden tanımlanmasına aracılık eden kongre ve sempozyum gibi bilimsel etkinliklerin içeriklerinin ele alınması bu değerlendirme yazısını önemli kılan etkenlerin başında gelmektedir. Ele alınan içerikler; kongrelerin, konferansların ve sempozyumların isimleri, gerçekleştirildikleri şehirler, tarihleri ve gerçekleştiren kurumların tasnif edilmesi şeklinde oluşturulmuştur. Ayrıca düzenlenen etkinliklerde ele alınan temel konu başlıkların neler olduğu da çalışma bağlamında ele alınan içeriklerden birisi olmuştur.

Yapılan bu çalışma bağlamında verilerin elde edilmesi sürecinde Google arama motoru üzerinden Kongre, Sempozyum, Konferans Arama Motoru, Kongre Uzmanı, Kongre Merkezi.Net Türkiye'nin Kongre Portalı ve Kongre \& Sempozyum isimli sayfalardan ve ayrıca bu etkinlikleri gerçekleştiren kurumların web siteleri üzerinden etkinliklere dair oluşturdukları içeriklerden yararlanılmıştır. Çalışma kapsamında gerçekleştirilen taramaların sonucunda sosyal ve beşeri bilimler alanında 2018 ve sonrasında toplam 164 tane etkinliğin düzenlendiği ve bu etkinliklerin 20 tanesinin iletişim alanına dair gerçekleştirilen etkinlikler olduğu tespit edilmiştir. Bu çalışmada elde edilen verilere göre genel olarak sosyal ve beşeri bilimler alanında yapılan etkinlikler içerisinde bir alt başlık olarak kendisine yer bulan iletişim alanının 2018 yılı ve sonrasında kendine özgü etkinlikler ile karşımıza çıktığı görülmektedir. Illetişim alanının gerek toplumsal yaşam pratiği içerisinde gerekse bireysel yaşam içerisinde hayatımızın her noktasına sirayet ettiği bir dönemde hinterlandını genişletmesi şaşırtıcı bir durum değildir.

Illetişim ve teknoloji arasında yaşanan bütünleşik birlikteliğin yapılan etkinliklere de yansıdığı görülmektedir. Düzenlenen etkinliklerin genel olarak teması "dijital" ve "iletişim" üzerine yoğunlaşmaktadır. Dijital çağda iletişim, dijital çağda reklam, dijital çağda gazetecilik, dijital halkla ilişkiler uygulamaları, dijital ağlar ve kamusal alan, dijital radyo yayıncılığı, dijital iletişimde çevrim içi sunum, dijital iletişim ve kültür, dijital medya ve bireyin temsili vb. başlıklar bu tema yoğunluğunun göstergesi niteliğindedir. 
Sosyal medya, yaşam pratiği içerisindeki ilişkilerini devam ettirme arzusunda olan her bireyin muhakkak olması gereken bir mecra olarak tıpkı bir hakikat gibi bireylere aktarılmış ve bireyler bu mecraları kullanma mecburiyeti hisseder hâle gelmiştir (Babacan, 2016, s. 524). Bu açıdan bakıldığında hayatımızın olmazsa olmazlarından birisi hâline gelen sosyal medyanın da yapılan etkinliklerin önemli bir bölümünün temasını oluşturuyor olması şaşırtıcı değildir. Sosyal medya kullanımı, sosyal medya ve birey, sosyal medyanın zararları, sosyal medyanın kullanım sıklığı, sosyal medyanın bilgi edinmedeki rolü vb. başlıkların yoğun bir şekilde ele alındığı görülmektedir. Yapılan bazı etkinliklerin ise iletişim ve iletişim eğitimi temaları üzerine yoğunlaştığı görülmektedir. Bu etkinliklerin içerisine dâhil edilen yazıların içeriği incelendiğinde son yıllarda ülkemizdeki üniversitelerde yeni iletişim fakültelerinin kurulduğu ve bu fakültelerde verilecek eğitimin doğru bir sistematik üzerine kurulması gerektiği tezinin ortaya konulduğu görülmektedir. Bu bağlamda iletişim ve sosyal yaşam, iletişim ve medya, iletişim ve kültürlerarası iletişim, iletişim ve eğitim gibi temalara yer verildiği saptanmıştır.

Illetişim disiplinler arası bir alanı temsil etmektedir. Bu açıdan iletişim alanının diğer alanlar ile ortak bir tema etrafinda bir araya gelmesi normal karşılanmaktadır. Bu normal içerisinde yer alan birlikteliklerden biri, siyaset ve iletişim kavşağında ortaya çıkan ve siyasal iletişim olarak adlandırılan bir birlikteliktir. İletişimin özünde bilgi aktarmak yer alırken siyasetin özünde de hedef kitle ile iletişim kurmak yer almaktadır. Çalışmamız bağlamında ele aldığımız etkinliklerde de bu birliktelik sonucunda ortaya çıkan siyasal iletişim kavramının tema olarak yer aldığı birçok çalışmanın olduğu görülmektedir. Siyaset ve medya, siyasal iletişim ve medya, siyasetin dijitalleşmesi, siyasette medyanın gücü gibi temaların sıklıkla işlendiği görülmektedir.

İletişim alanın modern toplum içerisinde önemli bir alanı kapsadığına dair görüşler 20. yüzyılın ilk dönemlerinden itibaren sıklıkla dile getirilmeye başlanmıştır. Yaşanan bu durum, iletişim alanın köklü bir disiplin özelliği kazanarak zengin içeriğe sahip bir araştırma alanına evirilmesini beraberinde getirmiştir. Illetişim alanı ile gündelik yaşam formu arasında kurulan organik ilişki bu alana dair birçok farklı konu başlığının ele alınarak detaylı bir şekilde tahlil edilmesini gerekli kılmıştır. Özellikle son 20-30 yıl içerisinde yaşanan teknolojik gelişmeler ve bu gelişmelerin toplumsal yaşam pratiği içerisinde sıklıkla kullanılan bir argüman hâline gelmesi iletişim alanına yönelik çalışmaların artmasını ve çeşitlilik kazanmasını sağlamıştır. Sonuç olarak yapılan bu çalışma bağlamında sosyal ve beşerî bilimler alanında iletişim alanını kapsayan kongrelerin, konferansların ve sempozyumların isimleri, tarihleri, mekân/ortamları ve bu etkinlikleri düzenleyen kurumlara yönelik bir 
içerik ortaya konulmaya çalışılmıştır. Yapılan çalışma bağlamında iletişim alanında yapılan etkinliklerin birçok farklı konu başlığı ile karşımıza çıktı̆̆ı görülmektedir. Bu etkinliklerde özellikle son yıllarda yaşanan teknolojik gelişmelere paralel olarak medya ve dijital ortam gibi genel konu başlıklarının sıklıkla ele alındığı görülmektedir. Daha özel konu başlıklarında ise yeni medya platformlarının bireylerin dünyasına nasıl nüfuz ettiği, değişen tüketim olgusu ve bu tüketim olgusuna yönelik medyanın etkisi, dijitalleşen tüketim anlayışı, medya ve siyaset arasındaki ilişki, medya ile mahremiyet, özgürlük, eşitlik, adalet ve kişisel haklar gibi kavramlar arasındaki ilişki gibi başlıklara değinildiği görülmektedir. Kısacası toplumsal yaşam pratiklerimizin vazgeçilmez unsurlarından biri olan iletişim alanının, yaşanan teknolojik gelişmeler ve dijitalleşen dünya neticesinde sosyal, siyasal ve kültürel anlamda yaşamımıza dair geniş perspektifteki etkileri ve bireylerin bu etki karşısındaki durumlarının ele alınan temaların ortak noktası olduğu görülmüştür. Özellikle dünya genelinde yaşanan kovid-19 salgını ile birlikte iletişim formunun değişmesi iletişim alanına yönelik çalışmaları arttıracak bir etken olarak öngörülmektedir. İncelenen çalışmaların temaları yoğunlukla "dijital, teknoloji ve iletişim" kavramları etrafinda şekillenmiştir. Bu perspektifte teknolojik gelişmeler sonucunda ortaya çıkan dijitalin bireyler üzerindeki etkisi ele alınırken, bireylerin dijital olanın üzerindeki etkisi ve bu etki sonucunda dijitalin yaşadığı form değişikliklerinin neler olduğu atıl kalmış bir konu başlığı olarak karşımıza çıkmaktadır. Dijital çağda bireyin durumunun iletişim ve sosyoloji kavşağında bir tartışma zemininde pek ele alınmadığı görülmektedir. Bireyin bu dijital çağdaki durumunu ve bu çağdan beklentilerini doğru okuyabilmek, bireyin kendini nasıl konumlandırdığını anlayabilmek adına sosyoloji başta olmak üzere diğer disiplinler ile ortak bir çalışma temasında buluşmanın faydalı olacağı öngörülmektedir. Ayrıca yapılan çalışmaların birçoğunda nicel verilerin ışığında sonuçlar ortaya konulurken sosyal bilimler içerisinde yer alan iletişim alanına yönelik nitel çalışmaların az olması da dikkat çeken unsurlardan bir tanesi olmuştur. Yapılan etkinliklerin ilk zamanlarda "iletişim" gibi çok genel bir tema çerçevesinde kurgulandığı görülürken daha sonra "iletişim ve medya", "dijital çağda iletişim" gibi daha spesifik temalar üzerinde kurgulandığı görülmektedir (ifig.uskudar.edu.tr, 2021). Özellikle son yıllarda iletişim alanına dair birçok alt başlığın meydana çıktığı düşünüldüğünde temaların daha spesifik seçilmesinin hazırlanan içerikler bağlamında da daha nitelikli eserlerin ortaya çıkması hususunda bir artı değer sağlayacağı öngörülmektedir. 
Türkiye'de İletişim Alanında Gerçekleştirilen Akademik Etkinlikler (2018-2020)

\begin{tabular}{|c|c|c|c|c|}
\hline Sira & Kongre, Sempozyum Adı & $\begin{array}{l}\text { Mekân ve } \\
\text { Ortam }\end{array}$ & Tarih & Üniversite/Kurum \\
\hline 1 & $\begin{array}{l}\text { 6.Uluslararası İletişim Gün- } \\
\text { leri Dijital Dönüşüm Sem- } \\
\text { pozyumu }\end{array}$ & $\begin{array}{l}\text { İstanbul- } \\
\text { Konferans } \\
\text { Salonu }\end{array}$ & $\begin{array}{l}\text { 02-03 Mayıs } \\
2019\end{array}$ & Üsküdar Üniversitesi \\
\hline 2 & $\begin{array}{l}\text { 7.Uluslararası İletişim Gün- } \\
\text { leri Dijital Çağda İletişim } \\
\text { Eğitimi Sempozyumu }\end{array}$ & $\begin{array}{l}\text { İstanbul - } \\
\text { Online }\end{array}$ & $\begin{array}{l}\text { 16-17 Nisan } \\
2020\end{array}$ & Üsküdar Üniversitesi \\
\hline 3 & $\begin{array}{l}\text { II. Marmara Lisansüstü Illeti- } \\
\text { şim Öğrencileri Kongresi }\end{array}$ & $\begin{array}{l}\text { İstanbul - } \\
\text { Konferans } \\
\text { Salonu }\end{array}$ & 7-8 Mayıs 2018 & $\begin{array}{l}\text { Marmara Üniversitesi } \\
\text { İletişim Fakültesi }\end{array}$ \\
\hline 4 & $\begin{array}{l}\text { III. Marmara Lisansüstü İle- } \\
\text { tişim Öğrencileri Kongresi }\end{array}$ & $\begin{array}{l}\text { İstanbul - } \\
\text { Konferans } \\
\text { Salonu }\end{array}$ & $\begin{array}{l}\text { 02-03 Mayıs } \\
2019\end{array}$ & $\begin{array}{l}\text { Marmara Üniversitesi } \\
\text { Illetişim Fakültesi }\end{array}$ \\
\hline 5 & $\begin{array}{l}\text { Çukurova Genç iletişimciler } \\
\text { Kongresi-2018 }\end{array}$ & $\begin{array}{l}\text { Adana - } \\
\text { Konferans } \\
\text { Salonu }\end{array}$ & $\begin{array}{l}\text { 03-04 Mayıs } \\
2018\end{array}$ & $\begin{array}{l}\text { Çukurova Üniversitesi } \\
\text { illetişim Fakültesi }\end{array}$ \\
\hline 6 & $\begin{array}{l}\text { Çukurova Genç iletişimciler } \\
\text { Kongresi-2019 }\end{array}$ & $\begin{array}{l}\text { Adana - } \\
\text { Konferans } \\
\text { Salonu }\end{array}$ & $\begin{array}{l}\text { 02-03 Mayıs } \\
2019\end{array}$ & $\begin{array}{l}\text { Çukurova Üniversitesi } \\
\text { îletişim Fakültesi }\end{array}$ \\
\hline 7 & $\begin{array}{l}\text { Uluslararası Dijital Çağda } \\
\text { illetişim Sempozyumu }\end{array}$ & $\begin{array}{l}\text { Mersin - } \\
\text { Konferans } \\
\text { Salonu }\end{array}$ & $\begin{array}{l}\text { 18-19 Ekim } \\
2018\end{array}$ & $\begin{array}{l}\text { Mersin Üniversitesi Illeti- } \\
\text { şim Fakültesi, İletişim } \\
\text { Fakülteleri Dekanlar } \\
\text { Konseyi (iLDEK) ve } \\
\text { İletişim Araştırmaları } \\
\text { Derneğinin }\end{array}$ \\
\hline 8 & $\begin{array}{l}\text { 2. Uluslararası Dijital Çağda } \\
\text { İletişim Sempozyumu }\end{array}$ & $\begin{array}{l}\text { İzmir - } \\
\text { Online }\end{array}$ & $\begin{array}{l}\text { 26-28 Ekim } \\
2020\end{array}$ & \begin{tabular}{|l} 
İzmir Ekonomi \\
Üniversitesi
\end{tabular} \\
\hline 9 & $\begin{array}{l}\text { ITICAM } 2020 \\
\text { Uluslararası Iletişim ve } \\
\text { Medyada Eğilimler ve So- } \\
\text { runlar Konferansı }\end{array}$ & - Online & $\begin{array}{l}\text { 03-04 Eylül } \\
2020\end{array}$ & $\begin{array}{l}\text { Bilim, Eğitim ve Tekno- } \\
\text { loji Derneği, Sakarya } \\
\text { Üniversitesi, Eğitim } \\
\text { İletişimi ve Teknolojisi } \\
\text { Derneği, Governors Eya- } \\
\text { let Üniversitesi, İstanbul } \\
\text { Üniversitesi, Türkiye } \\
\text { Yüksek Öğretim Kalite } \\
\text { Konseyi, Kıbrıs Uluslara- } \\
\text { rası Üniversitesi }\end{array}$ \\
\hline 10 & $\begin{array}{l}\text { İnönü Üniversitesi İletişim } \\
\text { Fakültesi } 1 \text {. Uluslararası } \\
\text { İletişim ve Yönetim Bilimleri } \\
\text { Kongresi }\end{array}$ & $\begin{array}{l}\text { Malatya - } \\
\text { Konferans } \\
\text { Salonu }\end{array}$ & $\begin{array}{l}\text { 26-27-28 Eylül } \\
2019\end{array}$ & \begin{tabular}{|l} 
İnönü Üniversitesi \\
iletişim Fakültesi
\end{tabular} \\
\hline 11 & $\begin{array}{l}\text { 2. Uluslararası Iletişim Bi- } \\
\text { limi \& Medya Çalışmaları } \\
\text { Kongresi }\end{array}$ & $\begin{array}{l}\text { İstanbul - } \\
\text { Konferans } \\
\text { Salonu }\end{array}$ & $\begin{array}{l}01-04 \text { Kasım } \\
2017\end{array}$ & $\begin{array}{l}\text { Kocaeli Üniversitesi İle- } \\
\text { tişim Fakültesi, İstanbul } \\
\text { Ayvansaray Üniversitesi }\end{array}$ \\
\hline
\end{tabular}




\begin{tabular}{|c|c|c|c|c|}
\hline 12 & $\begin{array}{l}\text { 3. Uluslararası Medya Çalış- } \\
\text { maları Sempozyumu }\end{array}$ & $\begin{array}{l}\text { Antalya - } \\
\text { Konferans } \\
\text { Salonu }\end{array}$ & $\begin{array}{l}\text { 01-03 Kasım } \\
2018\end{array}$ & $\begin{array}{l}\text { Akdeniz Üniversitesi } \\
\text { İletişim Fakültesi }\end{array}$ \\
\hline 13 & $\begin{array}{l}\text { 3.Uluslararası Kültürel Bi- } \\
\text { lişim \& Iletişim ve Medya } \\
\text { Çalışmaları Konferansı }\end{array}$ & $\begin{array}{l}\text { Aydın - } \\
\text { Online }\end{array}$ & $\begin{array}{l}\text { 20-22 Nisan } \\
2020\end{array}$ & $\begin{array}{l}\text { University of the Aege- } \\
\text { an, Aydın Adnan Men- } \\
\text { deres Üniversitesi }\end{array}$ \\
\hline 14 & $\begin{array}{l}\text { 1. Uluslararası } \\
\text { Yeni Dünyada } \\
\text { İletişim Kongresi } \\
\end{array}$ & $\begin{array}{l}\text { Adana - } \\
\text { Konferans } \\
\text { Salonu } \\
\end{array}$ & $\begin{array}{l}22-23 \text { Şubat } \\
2020\end{array}$ & - \\
\hline 15 & $\begin{array}{l}\text { Yeni Medya Çalışmaları IV. } \\
\text { Ulusal Kongre }\end{array}$ & $\begin{array}{l}\text { - Konfe- } \\
\text { rans Sa- } \\
\text { lonu }\end{array}$ & $\begin{array}{l}\text { 04-05 Ekim } \\
2019\end{array}$ & $\begin{array}{l}\text { Alternatif Bilişim } \\
\text { Derneği }\end{array}$ \\
\hline 16 & $\begin{array}{l}\text { II. Gelenekselden Dijitale } \\
\text { Uluslararası Medya Araştır- } \\
\text { maları Sempozyumu }\end{array}$ & $\begin{array}{l}\text { İzmir - } \\
\text { Online }\end{array}$ & $\begin{array}{l}10-11 \text { Aralık } \\
2020\end{array}$ & $\begin{array}{l}\text { Ege Üniversitesi İletişim } \\
\text { Fakültesi }\end{array}$ \\
\hline 17 & $\begin{array}{l}\text { 2. Uluslararası } \\
\text { Yeni Dünyada } \\
\text { İletişim Kongresi }\end{array}$ & $\begin{array}{l}\text { Ankara - } \\
\text { Online }\end{array}$ & $\begin{array}{l}02-04 \text { Ekim } \\
2020\end{array}$ & - \\
\hline 18 & $\begin{array}{l}\text { 3. Uluslararası } \\
\text { Yeni Dünyada } \\
\text { İletişim Kongresi }\end{array}$ & $\begin{array}{l}\text { Amerika - } \\
\text { Online }\end{array}$ & $\begin{array}{l}13-15 \text { Kasım } \\
2020\end{array}$ & - \\
\hline 19 & $\begin{array}{l}\text { Yeni Medya Çalışmaları IV. } \\
\text { Ulusal Kongresi }\end{array}$ & $\begin{array}{l}\text { İzmir - } \\
\text { Konferans } \\
\text { Salonu } \\
\end{array}$ & $\begin{array}{l}\text { 04-05 Ekim } \\
2019\end{array}$ & $\begin{array}{l}\text { Alternatif Bilişim } \\
\text { Derneği }\end{array}$ \\
\hline 20 & $\begin{array}{l}\text { Dijital Dönüşüm ve } \\
\text { İnovasyon: } \\
\text { 4. Uluslararası Yeni Medya } \\
\text { Konferansı }\end{array}$ & $\begin{array}{l}\text { İstanbul - } \\
\text { Konferans } \\
\text { Salonu }\end{array}$ & $\begin{array}{l}\text { 25-26 Nisan } \\
2019\end{array}$ & $\begin{array}{l}\text { İstanbul Gelişim } \\
\text { Üniversitesi }\end{array}$ \\
\hline
\end{tabular}




\section{Kaynakça}

2019.yenimedya.org.tr. (2021, 4 10). https://2019.yenimedya.org.tr/. https://2019.yenimedya.org.tr/: https://2019.yenimedya.org.tr/ adresinden alındı

Babacan, M. E. (2016). Yeni Medya ve Toplumsal İktidar Bağlamında Özne. Çankırı Karatekin Üniversitesi Sosyal Bilimler Enstitüsü Dergisi, 524.

Balcı , A. (2008). Türkiye'de Eğitim Yönetiminin Bilimleşme Düzeyi. Kuram ve Uygulamada Eğitim Yönetimi(54), 181-209.

cida.mersin.edu.tr. (2021, 3 28). http://cida.mersin.edu.tr/assets/kitaptammetinson. pdfv. http://cida.mersin.edu.tr: http://cida.mersin.edu.tr/assets/kitaptammetinson.pdf adresinden alındı

cida2020.ieu.edu.tr. (2021, 4 1). https://cida2020.ieu.edu.tr/index.php/cagri-metni/. https://cida2020.ieu.edu.tr: https://cida2020.ieu.edu.tr/index.php/ cagri-metni/ adresinden alındı

egeajans.ege.edu.tr. (2021, 4 10). https://egeajans.ege.edu.tr/?p=13548. https://egeajans.ege.edu.tr: https://egeajans.ege.edu.tr/?p=13548 adresinden alındı

ifig.uskudar.edu.tr. (2021, 3 10). https://ifig.uskudar.edu.tr/2019. https://www.ifig.uskudar.edu.tr/2019: https://ifig.uskudar.edu.tr/2019 adresinden alındı

ifig.uskudar.edu.tr. (2021, 3 11). https://ifig.uskudar.edu.tr/uploads/content/files/ifig2020-program.pdf. https://www.ifig.uskudar.edu.tr: https://ifig.uskudar. edu.tr/uploads/content/files/ifig-2020-program.pdf adresinden alındı

iletisim.ege.edu.tr. (2021, 4 9). https://iletisim.ege.edu.tr/tr-10544/ims_2020_hakkinda.html. https://iletisim.ege.edu.tr: https://iletisim.ege.edu.tr/tr-10544/ ims_2020_hakkinda.html adresinden alındı

ims.akdeniz.edu.tr. (2021, 4 5). http://ims.akdeniz.edu.tr. http://ims.akdeniz.edu.tr/ wp-content/uploads/2018/11/ims-.pdf: http://ims.akdeniz.edu.tr/ wp-content/uploads/2018/11/ims-.pdf adresinden alındı

iticam.net. (2021, 4 2). http://iticam.net/. http://iticam.net/: http://iticam.net/ adresinden alındı

kongreara.com. (2021, 4 3). https://kongreara.com/detay/iletisim/international-trends-and-issues-in-communication--media-conference---iticam-2019--181518. https://kongreara.com: https://kongreara.com/ detay/iletisim/international-trends-and-issues-in-communication--media-conference---iticam-2019--181518 adresinden alındı

Oplatka, I. (2012). Management in Education. The 2011 BELMAS Conference: New Topics, Diverse Ideas, Much More International Than Before, (s. 21-27). İsrail.

www.academia.edu.tr. (2021, 3 16). https://www.academia.edu/40710053/\%C4\%BOn\%C3\%B6n\%C3\%BC_\%C3\%9Cniversitesi_\%C4\%BOleti\%C5\%9Fim_Fak\%C3\%BCltesi_1_Uluslararas\%C4\%B1_\%C4\%B0leti\%C5\%9Fim_ve_Y\%C3\%B6netim_Bilimleri_Kongre_Tam_Metin_Bildiri_Kitab\%C4\%B1_26_09_2019_ by_Medya_Okuryazarl\%C4\%B1\%C4\%9F\%C4\%. https://www.academia. edu.tr. adresinden alındı

www.bilimsenligi.com.tr. (2021, 4 4). https://www.bilimsenligi.com/2-uluslararasi-iletisim-bilimi-medya-calismalari-kongresi.html/. https://www.bilimsenligi. com.tr: https://www.bilimsenligi.com/2-uluslararasi-iletisim-bilimi-medya-calismalari-kongresi.html/ adresinden alındı 
www.bilimsenligi.com.tr. (2021, 4 6). https://www.bilimsenligi.com/3-uluslararasi-kulturel-bilisimiletisim-ve-medya-calismalari-konferansi.html/. https://www.bilimsenligi.com.tr: https://www.bilimsenligi.com/3-uluslararasi-kulturel-bilisimiletisim-ve-medya-calismalari-konferansi.html/ adresinden alındı

www.cugenciletisimcilerkongresi.org. (2021, 3 19). https://www.cugenciletisimcilerkongresi.org/kabul-edilen-bildiri-ozetleri-2018/\#sayfa1. https://www.cugenciletisimcilerkongresi.org: https://www.cugenciletisimcilerkongresi.org/ kabul-edilen-bildiri-ozetleri-2018/\#sayfa1 adresinden alındı

www.ieu.edu.tr. (2021, 3 25). https://www.ieu.edu.tr/tr/news/type/read/id/7290. https://www.ieu.edu.tr: https://www.ieu.edu.tr/tr/news/type/read/id/7290 adresinden alındı

www.kongreuzmani.com. (2021, 4 9). https://www.kongreuzmani.com/kamu-bilgi-ve-iletisim-teknolojileri-konferansi-2020.html. https://www.kongreuzmani. com: https://www.kongreuzmani.com/kamu-bilgi-ve-iletisim-teknolojileri-konferansi-2020.html adresinden alındı

www.kongreuzmani.com.tr. (2021, 4 7). https://www.kongreuzmani.com/1-uluslararasi-yeni-dunyada-iletisim-kongresi.html. https://www.kongreuzmani.com. tr: https://www.kongreuzmani.com/1-uluslararasi-yeni-dunyada-iletisim-kongresi.html adresinden alındı

www.marmara.edu.tr. (2021, 3 14). https://www.marmara.edu.tr/event/3-marmara-lisansustu-iletisim-ogrencileri-kongresi. https://www.marmara.edu.tr: https://www.marmara.edu.tr/event/3-marmara-lisansustu-iletisim-ogrencileri-kongresi adresinden alındı

www.marmara.edu.tr. (2021, 3 12). https://www.marmara.edu.tr/event/marmara-lisansustu-iletisim-ogrencileri-kongresi-ii-cagri-metni. https://www.marmara. edu.tr: https://www.marmara.edu.tr/event/marmara-lisansustu-iletisim-ogrencileri-kongresi-ii-cagri-metni adresinden alındı

www.marmara.edu.tr. (2021, 3 13). https://www.marmara.edu.tr/event/marmara-lisansustu-iletisim-ogrencileri-kongresi-ii-cagri-metni. https://www.marmara. edu.tr: https://www.marmara.edu.tr/event/marmara-lisansustu-iletisim-ogrencileri-kongresi-ii-cagri-metni adresinden alındı

yenimedya.wordpress.com.tr. $\quad(2021,4$ 8). https://yenimedya.wordpress. com/2019/10/07/yeni-medya-calismalari-iv-ulusal-kongre-genel-degerlendirme-ve-sonuc-bildirgesi/. https://yenimedya.wordpress.com.tr: https://yenimedya.wordpress.com/2019/10/07/yeni-medya-calismalari-iv-ulusal-kongre-genel-degerlendirme-ve-sonuc-bildirgesi/ adresinden alındı 